\title{
Percepções Maternas Sobre o Tornar-se Avó no Contexto da Gravidez na
}

\author{
Adolescência \\ Meiridiane Domingues de Deus* \\ Universidade Federal de Santa Catarina - UFSC, Florianópolis, SC, Brasil \\ ORCID: http://orcid.org/0000-0002-9322-0162 \\ Ana Cristina Garcia Dias** \\ Universidade Federal do Rio Grande do Sul - UFRGS, Porto Alegre, RS, Brasil \\ ORCID: https://orcid.org/0000-0003-2312-3911
}

\section{RESUMO}

O presente estudo objetivou conhecer as percepções de 12 mulheres na faixa etária dos 29 aos 55 anos sobre o processo de tornar-se avó no contexto da gravidez adolescente. As informações foram coletadas em quatro Unidades Básicas de um município do Interior do Rio Grande do Sul por meio de entrevistas semiestruturadas. As análises das informações basearam-se no modelo teórico da Grounded Theory. Os resultados evidenciaram que o momento de tornar-se avó foi permeado por sentimentos e pensamentos negativos e positivos. As participantes não imaginavam que seriam avó neste momento de suas vidas. Para elas, ser avó é ser uma segunda mãe da criança. Ressalta-se a necessidade de maior atenção aos familiares envolvidos no contexto da gravidez adolescente, o que pode contribuir para entendimento da dinâmica familiar dos adolescentes, aspecto importante no planejamento, controle e execução de programas e intervenções de prevenção à gravidez na adolescência e estímulo da participação dos pais nas ações e orientações relativas a conversar sobre sexualidade nesta fase da vida. Sugere-se a realização de estudos com a percepção das avós maternas e paternas, bem como os avôs maternos e paternos no contexto da gravidez adolescente.

Palavras-chave: avós, gravidez na adolescência, teoria fundamentada.

\section{Maternal Perceptions About Becoming Grandmother in the Context of}

\section{Teenage Pregnancy}

\begin{abstract}
This study aimed to acknowledge the perceptions of 12 women in the age group of 29 to 55 years old about the process of becoming a grandmother in the context of teenage pregnancy. Information was collected in four Primary Healthcare Centers in an inland town of Rio Grande do Sul, Brazil, through semi-structured interviews. Data analysis was based on the theoretical model of Grounded Theory. Results showed that the moment of becoming a
\end{abstract}


grandmother was filled of negative and positive feelings and thoughts. Participants have not conceived being grandmothers at this point of their lives. For them, being a grandmother is like being a second mother of the child. It is highlighted the need for greater attention to family members involved in the context of teenage pregnancy, which might contribute to comprehend the family dynamics of adolescents, an important aspect in planning, control and execution of programs and interventions to prevent teenage pregnancy and stimulate parental involvement in actions and guidelines for discussing sexuality at this stage of life. For further studies, it is suggested the investigation of maternal and paternal grandparents perceptions in the context of teenage pregnancy.

Keywords: grandmother, adolescent pregnancy, grounded theory.

\section{Percepciones Maternas Acerca del Volverse Abuela en el Contexto del}

\section{Embarazo en la Adolescencia}

\section{RESUMEN}

Esta investigación buscó conocer las percepciones de 12 mujeres entre 29 a 55 años sobre el proceso de volverse abuela en el contexto del embarazo adolescente. Las informaciones fueron recogidas en cuatro Centros de Salud Primaria de una ciudad del interior de la provincia de Rio Grande do Sul, Brasil, a través de entrevistas semiestructuradas. El análisis de las informaciones se fundamentó en el modelo teórico de la Teoría Fundamentada. Los resultados indican que el momento de volverse abuela fue enredado por sentimientos y pensamientos negativos y positivos. Las participantes no imaginaban que iban a ser abuelas en este momento de sus vidas. Para ellas, ser abuela es ser una segunda madre del niño. Se subraya la necesidad de una mayor atención a los familiares involucrados en el contexto del embarazo adolescente, lo que puede contribuir a la comprensión de la dinámica familiar de los adolescentes, aspecto importante a la planificación, control y ejecución de programas e intervenciones de prevención al embarazo adolescente y estímulo de la participación de los padres en acciones y orientaciones con relación al dialogar sobre sexualidad con adolescentes. Se sugiere la realización de estudios sobre la percepción de abuelas y abuelos maternos y paternos en el contexto del embarazo adolescente.

Palabras clave: abuelas, embarazo en la adolescencia, teoría fundamentada.

O processo de tornar-se avó constitui-se em um período de transição (Becker \& Falcão, 2016), visto que este momento delimita a passagem para uma nova fase no ciclo vital, permeada por transformações na vida familiar, não somente em sua estrutura, mas também novos papeis são adquiridos e desempenhados pelos membros da família (Brás \& Pereira, 2011; Dias \& Teixeira, 2010; Kipper \& Lopes, 2006). É iniciado pela gravidez da filha ou 
quando os filhos tornam-se pais e continua ao longo do desenvolvimento da criança (Shlomo, Ben-Ari, Findler, Sivan, \& Dolizki, 2010; Taubman, Ben-Ari, Shlomo, \& Findler, 2012).

No contexto da gravidez na adolescência, as famílias, principalmente os pais das adolescentes, podem ser importantes fontes de apoio nos cuidados iniciais do bebê e na organização da vida das filhas (trabalho, casamento e estudo) (Dias, Patias, Gabriel, \& Teixeira, 2012; Hoga, Borges, \& Alvarez, 2009, Munslinger, Silva, De Bortoli, \& Guimarães, 2016). Os avós podem oferecer suporte emocional, carinho, afeto e apoio tanto para as filhas como para os (as) netos (as) (Deus \& Dias, 2016).

De fato, um estudo longitudinal realizado por Zeiders, Umaña-Taylor, Jahromi e Updegraff (2015) que examinou os processos intergeracionais relacionados aos valores familiares de avós, mães adolescentes e crianças mexicanas encontrou que os valores familiares das avós anteriores à maternidade das filhas conseguiam predizer os níveis de apoio e comunicação das avós às mães jovens. Observou-se que quanto maior os níveis de apoio oferecidos pelas avós às suas filhas melhores eram os níveis de autoeficácia das filhas, o que, por sua vez, conseguia predizer melhores resultados em termos de competência social das crianças aos 48 meses de idade. Este estudo demonstrou a importância de se estudar impacto dos valores familiares na situação de gestação na adolescência.

Para algumas mulheres, ser avó pode significar que serão co-educadoras (Dias, Hora, \& Aguiar, 2010), para outras, constitui-se em serem mães substitutas dos (as) netos (as) (Cardoso \& Brito, 2014; Mainetti \& Wanderbroocke, 2013; Pinto, Arrais, \& Brasil, 2014), ou ainda orientadoras das filhas na criação e educação dos netos de modo a transmitir seus conhecimentos (Zanatta \& Arpini, 2017). Nesse sentido, constituem-se em importante referência, fonte de suporte e de identificação para as adolescentes (Álvarez-Nieto, PastorMoreno, Linares-Abad, Serrano-Martos, \& Rodríguez-Olalla, 2014).

Em algumas situações, as mães de adolescentes mães assumem o papel de provedoras de apoio financeiro e emocional das filhas, o que pode contribuir para o amadurecimento da adolescente e para o desenvolvimento do bebê (Fernandes, Santos Júnior, \& Gualda, 2012). Em outros casos, as mães também vivenciaram a gravidez durante a adolescência e partilham com as filhas suas experiências de modo a apoiá-las (Cunha \& Wendling, 2011; Dias et al., 2012). Em uma pesquisa realizada na Colômbia, com mães adolescentes com idade entre 13 e 19 anos, observou-se que as avós maternas são fontes importantes no provimento de informações, suporte emocional e afetivo para as filhas que se tornaram mães adolescentes (Bossa \& Aponte, 2010). 
No período de descoberta da ocorrência da gravidez adolescente, as avós dos bebês, muitas vezes, expressam reações desfavoráveis ao evento, apresentando sentimentos de desgosto, tristeza, medo e rejeição associados especialmente a preconceitos sociais envolvidos no fenômeno (Gonçalves \& Knauth, 2006). As avós frequentemente realizam críticas ao evento de uma gravidez precoce e ao comportamento da gestante (Fernandes et al., 2012). Em outros casos, esse evento pode estar associado à alegria e satisfação (Souza, Brito, Frota, \& Nunes, 2012). Frequentemente, após um período inicial de desgosto, choque, culpa e frustração, a família passa a ser a principal fonte de apoio das jovens durante esse período da vida (Valila et al., 2011). Assim, o processo de tornar-se avó durante a gestação adolescente está associado tanto a emoções e concepções negativas como positivas (Shlomo et al., 2010). Muitas vezes, as mães das adolescentes possuem pouca idade e não imaginam ter que desempenhar o papel de avó precocemente. Muito embora, atualmente, existem mulheres que são avós com 35 anos como também aquelas que vivenciam esse momento tardiamente, por volta dos 70 anos (Cardoso, 2011).

Silva e Salomão (2003), ao estudar a relação entre a avó materna e a mãe adolescente, encontraram três possibilidades de vivência do fenômeno: em uma primeira, a avó assume as responsabilidades pelo cuidado da criança integralmente; em uma segunda, o papel materno da adolescente é inibido por concepções negativas da avó materna em relação à gestação/maternidade da filha; e uma terceira vivência, na qual a adolescente assume as responsabilidades pelos cuidados com a criança e a avó apenas acompanha e apoia a filha no cumprimento de suas funções com o bebê. As avós orientam, apoiam, preparam as filhas para o cuidado da criança. Algumas delas transmitem conhecimentos e orientações influenciados por experiências anteriores e crendices, e mesmo assim, realizam um bom suporte e auxílio às filhas (Santos, Teston, Cecílio, Serafim, \& Marcon, 2015).

Observa-se que as mães das adolescentes grávidas, frequentemente, possuem uma participação ativa na família extensa, e sua colaboração pode ser renovada no momento em que se tornam avós (Kipper \& Lopes, 2006). Esse momento envolve novas expectativas de vida e experiências emocionais, permeadas por sentimentos ambivalentes, como medo e alegria (Frisman, Eriksson, Pernehed, \& Morelius, 2012). Alguns estudos descrevem que a possibilidade de tornar-se avó possibilita a mulher, uma segunda chance. Ela pode buscar reparar as oportunidades perdidas na criação dos filhos, o que se associa a possiblidade de concretizar sonhos e desejos que não puderam ter sido realizados anteriormente, com os próprios filhos (Kipper \& Lopes, 2006). Por outro lado, a participação das avós na vida dos netos, implica no consentimento dos filhos para esse envolvimento. Dado a complexidade 
desse fenômeno, alguns autores (Kipper \& Lopes, 2006; Shlomo et al., 2010) constataram que o processo de se tornar avó tem recebido pouca atenção dos pesquisadores e pode representar um importante processo de transição na vida de uma mulher. Nesse sentido, o presente estudo busca conhecer as percepções de mulheres sobre o processo de tornar-se avó no contexto da gravidez adolescente.

\section{Método}

\section{Participantes}

Participaram do estudo 12 avós maternas com idades entre 29 e 55 anos $(M=38$ anos; $D P=7,0)$. Os critérios de inclusão na pesquisa foram: (1) ter uma filha adolescente gestante com idade entre 10 e 19 anos, conforme a Organização Mundial de Saúde (Brasil, 2006), que frequentava um programa de pré-natal em uma das Unidades Básicas de Saúde de um município do interior do Rio Grande do Sul e, (2) ser avó pela primeira vez. Os critérios de exclusão na pesquisa foram: (1) possuir alguma dificuldade cognitiva para compreender as questões das entrevistas; (2) a filha adolescente gestante apresentar algum transtorno mental.

Guest, Bunce e Johnson (2006) propõem que 12 participantes componham as amostras que utilizam o método da Grounded Theory. Para esses autores, as primeiras 12 entrevistas fornecem uma amplitude de temas que possibilitam a categorização do fenômeno, especialmente quando os dados apresentam informações em profundidade. Esse estudo buscou atingir a saturação teórica das informações, de modo que a coleta de novas informações não necessariamente possibilitaria o despertar de novos insigths teóricos ou geraria diferenças nas categorias teóricas apresentadas (Charmaz, 2009).

As filhas adolescentes primíparas tinham idades entre 13 e 19 anos $(M=17$ anos, $D P=$ 1,0). O tempo de gestação dessas variou de 4 meses a 7 meses ( $M=5$ meses), período em que as mães já estavam cientes da ocorrência da gestação da filha. Todas adolescentes ainda mantinham relacionamento afetivo com o pai dos bebês. Nem todas adolescentes residiam com suas mães, cinco moravam com os namorados, um com os avós maternos e dois irmãos, um com os pais, um junto com a mãe, um com pais e o namorado, um com pais, irmãos e namorado, um com a mãe, irmã e avós maternos e um com os sogros. As informações estão descritas na Tabela 1. 
Tabela 1

Dados socioeconómicos das participantes

\begin{tabular}{|c|c|c|c|c|c|c|c|c|}
\hline Nome & Idade & $\begin{array}{l}\text { Estado } \\
\text { civil }\end{array}$ & $\begin{array}{l}\text { Auto- } \\
\text { declaraçào } \\
\text { criterio } \\
\text { raça cor }\end{array}$ & $\begin{array}{l}\text { Trabalha } \\
\text { (profissão) }\end{array}$ & $\begin{array}{l}\text { Renda } \\
\text { Mensal }\end{array}$ & Escolaridade & $\begin{array}{l}\text { Idade } \\
\text { (mǎe)* }\end{array}$ & $\begin{array}{c}\text { Idade } \\
\text { (filha) }{ }^{* *}\end{array}$ \\
\hline Camélia & 29 & $\begin{array}{l}\text { Uniảo } \\
\text { Estável }\end{array}$ & Negra & Nảo & $\mathrm{R} \$ 2000,00$ & $\begin{array}{c}\text { Ensino } \\
\text { Fundamental } \\
\text { Completo }\end{array}$ & 13 & 16 \\
\hline Azaleia & 36 & Solteira & Parda & $\begin{array}{c}\text { Sim, } \\
\text { Garçonete } \\
\text { e auxiliar } \\
\text { de } \\
\text { cadeirante }\end{array}$ & $\mathrm{R} \$ 1200,00$ & $\begin{array}{l}\text { Ensino médio } \\
\text { Completo } \\
\text { (Técnico em } \\
\text { Enfermagem) }\end{array}$ & 15 & 18 \\
\hline Dália & 42 & Casada & Branca & $\begin{array}{c}\text { Sim, } \\
\text { Vendedora }\end{array}$ & R\$1500,00 & $\begin{array}{l}\text { Ensino Médio } \\
\text { Completo }\end{array}$ & 23 & 16 \\
\hline Gardènia & 35 & Casada & Branca & $\begin{array}{c}\text { Sim, } \\
\text { Auxiliar } \\
\text { de limpeza }\end{array}$ & $R S 1200,00$ & $\begin{array}{l}\text { Ensino Médio } \\
\text { Completo }\end{array}$ & 17 & 16 \\
\hline Tulipa & 46 & Divorciada & Branca & $\begin{array}{c}\text { Sim, } \\
\text { Atendente }\end{array}$ & $R \$ 1200,00$ & $\begin{array}{l}\text { Ensino Médio } \\
\text { Completo } \\
\text { (Técnico em } \\
\text { Contabilidade) }\end{array}$ & 26 & 19 \\
\hline Ins & 40 & Casada & Branca & $\begin{array}{c}\text { Sim, } \\
\text { Auxiliar } \\
\text { de limpeza }\end{array}$ & $\begin{array}{c}\text { RS } \\
2000,00\end{array}$ & $\begin{array}{l}\text { Ensino } \\
\text { Fundamental } \\
\text { incompleto }\end{array}$ & 19 & 18 \\
\hline Magnólia & 55 & Casada & Parda & Nà̃o & RS 800,00 & $\begin{array}{l}\text { Ensino } \\
\text { Fundamental } \\
\text { Incompleto }\end{array}$ & 37 & 19 \\
\hline Gérbera & 38 & Solteira & Parda & $\begin{array}{l}\text { Sim, } \\
\text { atendente } \\
\text { de loja }\end{array}$ & $\mathrm{R} \$ 1500,00$ & $\begin{array}{l}\text { Ensino Superior } \\
\text { (Administraçào) }\end{array}$ & 17 & 17 \\
\hline Angélica & 35 & Solteira & Parda & $\begin{array}{c}\text { Sim, } \\
\text { faxineira }\end{array}$ & RS 800,00 & $\begin{array}{l}\text { Ensino } \\
\text { Fundamental } \\
\text { Incompleto }\end{array}$ & 16 & 17 \\
\hline Jasmim & 40 & Solteira & Branca & $\begin{array}{l}\text { Sim, } \\
\text { artesã }\end{array}$ & $\mathrm{R} \$ 3000,00$ & $\begin{array}{l}\text { Ensino Médio } \\
\text { Completo }\end{array}$ & 19 & 19 \\
\hline Bromélia & 36 & Casada & Branca & Não & $\begin{array}{c}\text { RS } \\
2900,00\end{array}$ & $\begin{array}{l}\text { Ensino Médio } \\
\text { Completo }\end{array}$ & 20 & 15 \\
\hline Amarilis & 29 & Solteira & Branca & $\begin{array}{c}\text { Sim, } \\
\text { Atendente } \\
\text { de } \\
\text { locadora }\end{array}$ & $\begin{array}{c}\text { RS } \\
2500,00\end{array}$ & $\begin{array}{l}\text { Ensino Médio } \\
\text { Completo } \\
\text { (Técnico em } \\
\text { Administração) }\end{array}$ & 13 & 13 \\
\hline
\end{tabular}

\section{Instrumentos}

A coleta das informações foi realizada por meio da aplicação dos seguintes instrumentos: (1) questionário de dados socioeconômicos; (2) entrevista sobre a relação mãefilha e percepções sobre a gravidez da filha; (3) entrevista sobre o processo de tornar-se avó. Todos os instrumentos foram formulados pelas autoras desse estudo e versaram sobre gravidez na adolescência, sentimentos e reações frente à notícia da gestação, o processo de tornar-se avó e suas expectativas. 


\section{Procedimentos}

Coleta de dados. As informações foram gravadas, após autorização das participantes, de modo a preservar o sigilo e confidencialidade das mesmas. $\mathrm{O}$ estudo foi aprovado pelo Comitê de Ética de uma Universidade da região Sul do Brasil sob o parecer n 981.698 e autorizado pela Secretaria Municipal da Saúde, de um município da região central do Rio Grande do Sul. Foram adotadas as orientações oferecidas pelas Diretrizes e Normas Regulamentadoras de Pesquisa com Seres Humanos (Resolução nº. 466/2012) do Conselho Nacional de Saúde.

O trabalho foi desenvolvido em quatro Unidades Básicas de Saúde (UBS) do município. Inicialmente, foram triadas as informações nos prontuários e na ficha de cadastramento das gestantes contidas no programa SISPRENATAL (Sistema de Acompanhamento do Programa de Humanização no Pré-Natal e Nascimento).

Foram coletadas as seguintes informações sobre as gestantes: período gestacional; idade; contato telefônico; endereço. Por meio dessas buscou-se entrar em contato as mães (avós). Foram contatadas 80 adolescentes, sendo entrevistadas dessa forma apenas seis avós. Algumas foram excluídas, pois dez adolescentes contatadas já eram mães, uma adolescente havia perdido o bebê, vinte e cinco não atenderam ao telefone. Três pessoas contatadas pelo telefone não eram adolescentes. Algumas avós com quem se realizou contado também foram excluídas: quatorze já possuíam netos, uma avó (28 anos de idade) não aceitou participar da pesquisa por não se sentir à vontade em conversar sobre a gestação da filha, outra avó marcou a entrevista, mas desistiu; outra avó não compareceu a entrevista e duas avós moravam em outros municípios do Rio Grande do Sul. Em função das dificuldades de acesso as avós (informações incompletas nos prontuários, números de telefone inexistentes e errados) foi escolhida outra forma de coleta das informações. Optou-se por conversar também com as adolescentes e suas mães na sala de espera das consultas de pré-natal das UBS. Assim, as entrevistas podiam ser realizadas tanto nas residências das avós como nas UBS.

Análise de dados. A organização e a análise das informações foram desenvolvidas a partir do modelo teórico da Grounded Theory ou Teoria Fundamentada nos Dados (TFD). A análise se baseia na apresentação e reflexão sistemática do fenômeno em sucessivos capítulos, a fim de descrever as características, a origem, o contexto social e histórico das etapas da pesquisa por meio da codificação, análise, redação e a avaliação constante de todos os elementos que envolvem a investigação (Tarozzi, 2011). A elaboração das categorias ocorre por meio da codificação do conteúdo das entrevistas. Por meio de uma leitura exaustiva linha 
a linha foram destacados os conteúdos principais das perguntas. Esses fragmentos foram analisados, sistematizados e organizados conforme as semelhanças e a relevância das informações. As questões da entrevista que se mostraram importantes para compreensão do processo de tornar-se avó no contexto da gravidez adolescente foram: Como as mães (avós dos bebês) recebem a notícia da gravidez da filha adolescente?; Quais os sentimentos e pensamentos despertados nessas mulheres neste momento período?; Quais eram as expectativas dessas mulheres sobre ser avós neste momento de vida?; Quais as suas percepções do que é "ser avó"?. Essas questões foram organizadas em duas categorias, a saber: a notícia da gravidez da filha e as percepções do que é "ser avó".

\section{Resultados}

\section{Notícia da gravidez da filha}

Esta categoria é composta pelas percepções das avós sobre a notícia da gravidez da filha. Busca descrever o modo como as mães descobriram este evento, os sentimentos e pensamentos vividos com esta descoberta e se elas imaginavam ser avó neste momento de suas vidas. Nela, as participantes relataram que descobriram a gestação da filha através de diferentes formas: ligações telefônicas; teste de gravidez; publicação nas redes sociais; por intermédio de algum familiar como tias e/ou filhas (irmãs das adolescentes grávidas) ou em conversas com a adolescente. Os depoimentos a seguir ilustram essas situações. A filha contou por meio de uma ligação telefônica: "ela me ligou e contou” (Camélia, 29 anos); "ela me falou pelo telefone: mãe estou grávida" (Tulipa, 46 anos). Outra mãe realizou o teste de gravidez junto com a filha: "desconfiei, cuidei a menstruação dela e comprei o teste, fiquei sabendo pelo teste" (Angélica, 35 anos).

Outra avó ainda ficou sabendo da gestação da filha através de uma publicação nas redes sociais: "o namorado dela estava terminando o Trabalho de Conclusão de Curso dele colocou (nas redes sociais) os agradecimentos e colocou: a nova realização de ser pai” (Gérbera, 38 anos). A descoberta da gestação também ocorreu por meio de outros familiares, a exemplo da tia da adolescente (irmã da avó): "ela contou para a minha irmã, fizeram o exame, ela pegou o exame e atirou em cima da mesa, ai eu vi” (Dália, 42 anos) e da outra filha (irmã da gestante adolescente): "ela falou para a minha mãe e para a minha filha, fiquei sabendo pela outra filha” (Amarílis, 29 anos). A filha contou em uma conversa com a mãe: "ela me contou faceira" (Azaleia, 36 anos); "ela me falou, (...) estava grávida com dois 
meses de gestação" (Gardênia, 35 anos); "ela me contou” (Íris, 40 anos); "ela achou que estava com algo nos ruins, ai fez ultrassom e deu, ai me contou” (Jasmim, 40 anos); "ela me contou, (...) já estava com três meses" (Bromélia, 36 anos); "ela me contou, disse: mãe eu acho que eu estou grávida, queria te fazer essa surpresa”(Magnólia, 55 anos).

Diferentes sentimentos foram evocados nas participantes em função da descoberta da gestação da filha: (a) susto: "eu levei um susto (Íris, 40 anos), primeiro foi um baque" (Camélia, 29 anos); (b) raiva: "raiva, raiva, na hora raiva, agora estou aceitando" (Bromélia, 36 anos); (c) negação/ raiva/aborrecimento: "primeiro rejeitei a ideia, fiquei chateada, fiquei brava com a irresponsabilidade dela" (Jasmim, 40 anos); (d) medo: "senti medo dela passar trabalho, que ela sofra, que dê complicação” (Azaleia, 36 anos); (e) tristeza: "senti vontade de chorar, não era aquilo que eu queria para ela, é difícil" (Gardênia, 35 anos); "me entristeceu” (Angélica, 35 anos); (f) mágoa/ aborrecimento: "eu me senti meio estranha, fiquei magoada sabe, fiquei chateada, a última a saber” (Magnólia, 55 anos); (g) felicidade: "queria apertar as duas, mas estava distante" (Gérbera, 38 anos), "fiquei bastante feliz, por que pode ser que ela se tornando mãe ela cresça" (Amarílis, 29 anos). Os sentimentos também podiam ser ambivalentes (felicidade e pena) "eu fiquei feliz e ao mesmo tempo com pena dela, muito novinha" (Dália, 42 anos); (felicidade e pavor) "eu senti uma alegria e um pavor, por que sei o que é criar um filho quase sozinha” (Tulipa, 46 anos).

Os pensamentos associados à revelação das notícias e referiram principalmente as preocupações maternas com a situação futura da filha e ao cuidado com a criança, assim como sobre os motivos para a ocorrência da gravidez nessa fase da vida. Os excertos ilustram esses pensamentos: "me passou só coisa ruim na cabeça, eu passei muito trabalho por que eu casei por que engravidei dela” (Camélia, 29 anos), "E agora?” (Íris, 40 anos); “vai saber criar?” (Magnólia, 55 anos); “como é que vamos criar essa criança, é muita coisa” (Tulipa, 46 anos); "E o teu futuro?” (Azaleia, 36 anos).

Outros pensamentos e questionamentos giraram em torno dos motivos subjacentes a ocorrência da gravidez ou mesmo como lidar com a situação: "por que ela não se cuidou, por que ela não pensou” (Gardênia, 35 anos); "ela fez de propósito” (Jasmim, 40 anos); "agora está na hora de ter juízo, vem uma criança, é uma responsabilidade” (Angélica, 35 anos). Uma das participantes sugeriu a realização de um aborto à filha: "pensei até em abortar, vamos dar um jeito!” (Bromélia, 36 anos). Outra, por sua vez, pensou em assumir o bebê: “pensei em pegar a criança e criar” (Amarílis, 29 anos). Uma avó expressou um pensamento positivo: "eu estou sendo mãe de novo, eu não vejo a hora de nascer para proteger e estar junto" (Gérbera, 38 anos). Além disso, as avós Camélia (29 anos) e Azaleia (36 anos) 
relacionaram a gravidez das filhas as suas histórias de vida, pois foram mães durante a adolescência. Camélia (29 anos) relatou ter se assustado e ter pensamentos ruins em relação a gravidez da filha, pois "passou um filme de desde de que eu tive ela, eu espero que ela seja boa mãe, que nem eu fui para ela", a avó relatou sua experiência de gravidez na adolescência permeada de conflitos, brigas familiares e com seu companheiro. Já Azaleia (36 anos) afirma que pensou sobre o futuro da filha, e disse temia um futuro sofrimento da filha em função da gestação e criação do bebê. Embora oito das participantes tenham sido mães na adolescência, somente duas avós associaram a ocorrência da gravidez das filhas a suas próprias histórias.

Ao serem questionadas se imaginavam que seriam avós neste momento atual da vida foram unânimes em afirmar que "não". Algumas em função da idade como, por exemplo, "eu imaginava assim, com 43 anos, não com 29” (Camélia, 29 anos); "eu imaginava com uns 50 anos” (Dália, 42 anos); “eu dizia não quero ser avó cedo, não me vejo como avó”(Amarílis, 29 anos). Gérbera (38 anos) destacou que "me enxerguei até de bengala será que estou tão velhinha, não é a idade, agora me acostumei”. Gardênia (35 anos) afirmou que não estava preparada. Magnólia disse "agora vou ter que aguentar". As outras avós afirmaram que não se imaginava como avó neste momento de sua vida, o que se confirma nos seus relatos: "não, por que ela disse que não queria ter filho tão cedo" (Azaleia, 36 anos); "nunca, nunca imaginei”(Íris, 40 anos); "não, até às vezes nem me dou conta” (Angélica, 35 anos); “não, não estou preparada" (Gardênia, 35 anos). A idade precoce da gestação da filha esteve relacionada, como se pode ver, em alguns casos, às suas reações negativas em termos de sentimentos e pensamentos.

\section{Percepções do que é "ser avó"}

Esta categoria aborda as percepções das participantes sobre o que é ser avó. Além disso, descreve as responsabilidades que as avós esperam desempenhar nesta função. As participantes consideram a "avó" como uma segunda mãe do (a) neto (a). Destacam que as avós podem ter maior responsabilidade e respeito, que as mães: "eu tenho minha mãe que é a segunda mãe deles [filhos], eles respeitam mais ela” (Camélia, 29 anos); “a mãe (avó) tem o dobro de responsabilidade, tem que tomar conta da filha e da neta, duas vezes mãe" (azaleia, 36 anos). O envolvimento nas atividades e cuidados gerados pela gestação também despertaram em algumas participantes esse sentimento de ser uma segunda mãe, veja os depoimentos: "eu acho que é a mesma coisa que uma mãe” (Tulipa, 46 anos); "estou sentindo como se fosse meu filho" (Dália, 42 anos); "estou participando de tudo da gestação 
dela, das consultas, e depois quando ela ganhar vou estar presente, acho que é ser mãe de novo" (Gardênia, 35 anos); "é como se fosse um filho" (Íris, 40 anos); "é uma responsabilidade, é estar presente sempre, nas horas que mais precisa” (Angélica, 35 anos).

Por outro lado, são descritas algumas dificuldades referentes a adoção dessa nova função. As falas indicam que algumas consideraram precoce a gestação da filha, e estranharam essa nova situação. Os depoimentos ilustram: "é muito cedo, então eu disse para ela, eu vou ser madrinha dele (...) não me vejo como avó, mas vou dar todo apoio e carinho(Amarílis, 29 anos); "Parece uma palavra estranha, parece que não é para mim (...) jamais interferir no jeito da filha criar a criança, mas eu estarei observando a criação dada por ela" (Gérbera, 38 anos).

Ao serem questionadas sobre as responsabilidades de uma avó, descreveram que devem ajudar e orientar a filha a educar o (a) neto (a), oferecer afeto, carinho, paparicar os netos, além de auxiliar a filha nos cuidados, nas consultas médicas e na alimentação dos netos. Observe os relatos "estar atenta a tudo, orientar e ensinar a minha filha e ajudá-la" (Íris, 40 anos); “dar carinho, amor, atenção, levar ao médico, vacinar, preocupar-se com a alimentação da criança” (Angélica, 35 anos); “cuidar, eu vou fazer tudo” (Jasmim, 40 anos); "proteger sempre para o que der e vier" (Gérbera, 38 anos); "fazer as vontades do neto" (Magnólia, 55anos).

Por outro lado, Azaleia (36 anos) e Bromélia (36 anos) afirmaram que não irão cuidar dos netos para que suas filhas possam ir a festas: "eu não vou cuidar para ir para balada, fazer festa, mas para estudar, trabalhar, vou ser uma avó prestativa” (Azaleia, 36 anos); "jamais vou ficar para ela ir para a balada, se colocou no mundo, vai ter que cuidar, agora se disser, mãe vou trabalhar, vou estudar, ai é diferente, sou rígida neste ponto”. Algumas avós reconhecem que é importante não interferir na função materna desempenhada pela filha. Afirmam: "não posso passar por cima da minha filha, cada um cria a sua maneira" (Azaleia, 36 anos); “não quero tirar o papel da minha filha, vou auxiliá-la” (Amarílis, 29 anos). Outras já descreveram uma posição contrária a essa, indicando que irão interferir na educação ofertada pela filha aos neto(a)s, buscando realizar uma orientação da filha e neto(a) em termos de educação: “quero que ele estude, minha obrigação é educar” (Dália, 42 anos); "ajudar a educar" (Gardênia,35 anos); "vou ajudar, dar carinho e intervir na educação" (Bromélia, 36 anos). 


\section{Discussão}

A ocorrência da gravidez e as transformações advindas da maternidade na adolescência não somente irão ter reflexos na vida da adolescente, como também, poderão provocar mudanças na dinâmica familiar (Brás \& Pereira, 2011). Das 12 participantes da pesquisa, oito vivenciaram a gestação na adolescência. Alguns estudos como os de Cunha e Wendling (2011) e o de Dias et al. (2012) também descrevem que a situação de gravidez na adolescência pode ser uma experiência transgeracional. Neste estudo, apenas duas avós dos bebês descreveram que ao saberem da gestação da filha pensaram em suas próprias histórias de gravidez durante a adolescência. Essas informações sugerem que apesar da ocorrência apresentar esse caráter transgeracional, de repetição de modelos, como descrito por Cunha e Wendling (2011), isso pode não ocorrer de forma consciente.

Se por um lado, as mães que foram gestantes durante a sua adolescência podem ser mais compreensíveis à situação das filhas, apoiando-as neste momento de suas vidas (Silva \& Salomão, 2003); elas também podem apresentar uma reação mais negativa em relação à ocorrência da gestação, especialmente em função de suas próprias vivências de medo e de preconceito. No primeiro caso, as mães buscam oferecer apoio para enfrentar as representações negativas vinculadas ao período, no segundo caso, as mães podem compartilhar e reviver as próprias representações e experiências negativas relacionadas a gestação no período.

Gonçalves e Knauth (2006) descrevem que o conceito de "aproveitar a vida", assume grande destaque para compreender as narrativas sobre juventude e gravidez na adolescência. Essa expressão emergiu em uma pesquisa de cunho qualitativo, realizada em Pelotas/RS com 23 adolescentes, com idade entre 18 e 19 anos que já tinham filho(s) e com 10 mães desses jovens. Os depoimentos indicam que a adolescência/ juventude é um momento no qual o indivíduo deve se posicionar para viver a vida de uma forma proveitosa. Ou seja, há diversas representações, por vezes ambíguas, associadas a esse período da vida. Há uma coexistência entre as ideias de valorização da juventude (significa inicialmente sair, namorar, ficar, divertir-se, paquerar, dançar e curtir) e aquela de um período com atitudes criticáveis (imaturidade e inconsequência). Esse é um momento também de explorar, testar fronteiras valorativas e morais, que na atualidade são mais fluidas. A gravidez adolescente durante esse período enfatiza o lado oposto, o de vinculação com compromissos: filho; companheiro; casa; cônjuge. A gravidez é, então, percebida como um momento de rompimento criticado e moralizado que interrompe às qualidades positivas da vida juvenil. 
Por isso, a comunicação da notícia da gravidez da filha pode ocorrer de diferentes formas e independente da estratégia utilizada pelas adolescentes, muitas vezes, pode ser permeada pelo temor da reação dos familiares (Hoga et al., 2009; Munslinger et al., 2016). Tal como as participantes desse estudo que relataram que as filhas comunicaram a notícia da gestação por meio de ligação telefônica, conversa da mãe com a filha gestante, intermédio de familiares como avó materna, tia e irmã, através da confirmação do teste de gravidez, destacase o caso em que a avó ficou sabendo por meio de uma publicação realizada pelo seu genro nas redes sociais.

A literatura não traz muitos estudos sobre a forma de comunicação utilizada pela adolescente para noticiar a gestação, mas o estudo de Hoga et al. (2009) salienta que em alguns casos as mães são as primeiras a receberem a notícia, e em outros, são temidas, sendo escondida a gravidez pelo período máximo de tempo. Na segunda situação, outros familiares podem fazer a função de mediação de um possível conflito familiar gerado pela descoberta da gestação. Esses aspectos foram ilustrados no presente estudo pelas falas das avós em que algumas filhas preferiram contar para a tia ou para a irmã a contar para as suas mães, muito embora, a maioria tenha revelado o evento para as suas figuras maternas.

Nesse estudo também foi constatado o fato de que a descoberta da gravidez pode suscitar nos familiares das adolescentes reações e sentimentos negativos frente à situação, mas, após certo período estes, passam a aceitar, apoiar e preocupar-se com os aspectos relacionados à saúde tanto do bebê como da adolescente durante a gestação. Ao descobrir a gestação das filhas, as avós participantes relataram terem sentimentos negativos como: raiva, mágoa, susto, medo, rejeição e tristeza. O sentimento positivo destacado foi felicidade, sendo relatado por duas avós. Uma avó relatou ter sentimentos ambivalentes de pena e felicidade e outra, pavor e felicidade. O surgimento de reações desfavoráveis em relação à gravidez está relacionado aos preconceitos sociais e representações negativas, que indicam que esse fenômeno pode interromper a trajetória de vida dos jovens (Fernandes et al., 2012; Gonçalves \& Knauth, 2006).

Além disso, as reações negativas das mães das adolescentes podem estar relacionadas ao fato de que mudanças ocorridas neste período não afetam somente as adolescentes, mas modificam seus planos de vida pela necessidade de assumir uma nova função. Os pais das adolescentes geralmente ficam surpresos e assustados com a descoberta da gravidez, pois se questionam e, por vezes, sentem-se culpados uma vez que a gestação pode representar uma falha na função parental (Dias \& Teixeira, 2010). Outro fator que parece influenciar em uma reação negativa à gestação é que para mães das adolescentes, foi o fato delas se considerarem 
jovens para vivenciar de forma antecipada esse novo período de suas vidas - o de ser avó, que geralmente está associado a concepções desfavoráveis de envelhecimento como a perdas e declínio de outras habilidades (Becker \& Falcão, 2016).

Por outro lado, as representações de ser avó podem ser positivas. As autoras ainda referem que os avós podem contribuir para a resolução dos conflitos familiares e psicossociais, formar novos vínculos afetivos, reavaliar a vida e rever os erros do passado, além de exercerem uma influência positiva para os netos. Nesse sentido, as mães (agora avós) se constituem em uma referência, que representam uma importante fonte de suporte e de identificação para as adolescentes (Álvarez-Nieto et al., 2014). As avós dos bebês podem ser consideradas como orientadoras das filhas na criação e educação dos netos e fonte de transmissão de conhecimentos (Santos et al., 2015; Zanatta \& Arpini, 2017). No fenômeno da gestação adolescente, a relação entre a mãe e sua filha adolescente é fundamental, visto que a figura materna pode ser uma fonte fundamental de apoio, e a colaboração entre ambas pode contribuir para o amadurecimento da adolescente e no desenvolvimento do bebê (Fernandes et al., 2012).

Outro aspecto importante relatado pelas participantes foram os questionamentos sobre a capacidade da filha em criar uma criança. As mães relatam que ao pensar no futuro da filha podem sentir pena e preocupação. Os sentimentos de vergonha pela ocorrência da gravidez podem contribuir para o surgimento de desconfiança da maturidade da filha para o desempenho do papel materno. Uma das formas encontradas para resolver essa situação, que pode ser considerada um "problema" (Dias \& Teixeira, 2010), é a realização de um aborto. A pesquisa realizada por Silva e Salomão (2003) afirmou que 16\% das mães das adolescentes tentam convencer suas filhas a realização do aborto, em alguns casos as filhas e outros familiares não aceitam a sugestão. Isso também foi visto em nosso estudo, no qual a filha não aceitou a sugestão da mãe.

Por outro lado, observou-se que o momento de se tornar avó envolve novas expectativas de vida e experiências emocionais, além de sentimentos ambivalentes, como medo e alegria. (Frisman et al., 2012). Esse pode ser percebido como um momento de transição na vida dos indivíduos (Becker \& Falcão, 2016). Com a gravidez da filha, que se torna mãe, a mãe se torna avó, mesmo que essas mulheres vivenciam a "avosidade" em um momento diferente daquele esperado, no qual, tornar-se avó ocorre em um momento mais tardio da vida. Essa situação, ao mesmo tempo que pode despertar as características citadas como positivas descritas no estudo de Becker e Falcão (2016), podem ser vividas de forma tensa e preocupada, em função das novas responsabilidades que podem assumir (como 
criação do neto), o aumento dos gastos na família e os questionamentos se a filha dará conta dos cuidados da criança (Shlomo et al., 2010; Taubman et al., 2012). Embora a maioria dos avós se disponha a cuidar voluntariamente dos netos, isso não significa que o processo de tornar-se avó seja representado somente por vivências prazerosas. Há uma ideia de que os avós sejam pessoas "perfeitas", que conseguem resolver conflitos (Pinto, Arrais, \& Brasil, 2014), o que distancia seu exercício desses sentimentos e vivências ambivalentes ou mesmo conflituosos na condição de tornar-se avó.

No entanto, observou-se nos depoimentos das mães desse estudo que tornar-se avó pode favorecer o despertar de sentimentos positivos e proporcionar crescimento pessoal. Para algumas mulheres, ser avó é ter uma função similar à materna (Mainetti \& Wanderbroocke, 2013). Outras, afirmaram que a função da avó é melhor que ser mãe, visto que já possui experiência e por isso, conseguem lidar melhor com os problemas familiares e dos netos (Cardoso \& Brito, 2014). Algumas avós se consideram co-educadoras (Dias, Hora, \& Aguiar, 2010), outras, afirmam serem mães substitutas dos netos (Cardoso \& Brito, 2014; Pinto et al., 2014). Em muitas famílias, as avós são as responsáveis pela educação, saúde, vida escolar e cuidados diários dos netos (Mainetti \& Wanderbroocke, 2013). Além disso, são fonte de apoio, carinho e afeto para os netos (Dias et al., 2010). A oportunidade de ser avó faz com que se tenha a possibilidade de reparar momentos perdidos na criação dos seus filhos e possibilitar a mulher, uma segunda chance de reparar oportunidades perdidas, de modo a permitir a concretização dos sonhos, desejos e ideais que as avós não puderam concretizar (Kipper \& Lopes, 2006).

As avós quando interrogadas em relação a ser avó neste momento atual de vida foram unânimes em afirmar que não estavam preparadas. Destaca-se a idade precoce das avós, na faixa etária dos 29 aos 55 anos, com média de idade de 38 anos. Na atualidade, a idade em que os indivíduos se tornam avós é diferente daquela que era considerada padrão antigamente, visto que tanto é possível observar avós com idades consideradas precoces como 35 anos até indivíduos que se tornam avós mais tardiamente, a partir dos 70 anos (Cardoso, 2011).

O estudo realizado por Kipper e Lopes (2006) com 11 avós maternas com idades entre 49 e 66 anos, sendo a criança o seu primeiro neto constatou que nove das avós pesquisadas tinham expectativas de ser avó, pois já se consideravam na idade para exercer essa função. Dado que vai de encontro ao relato das avós desse estudo, visto que algumas desconsideravam essa possibilidade de ser avó em função da sua idade e de suas filhas. Algumas avós destacaram não quererem ser avós novas, em função do imaginário social em relação à figura das avós, tal como retrata uma das participantes "me enxerguei até de bengala 
será que estou tão velhinha". Isso retrata a figura clássica da vovozinha na cadeira de balanço, cabelos brancos fazendo tricô ou crochê, presente na literatura infantil, representação que pouco corresponde ao atual perfil das avós, em função das mudanças na família.

\section{Considerações Finais}

Este estudo qualitativo objetivou conhecer as percepções de 12 mulheres sobre o processo de tornar-se avó no contexto da gravidez adolescente. A realização desse estudo contribui para o conhecimento da percepção das mães das adolescentes sobre o evento da gestação das filhas e perspectivas em relação à função de avó e nascimento da criança no contexto da gravidez na adolescência.

Os resultados do estudo evidenciam que o processo de tornar-se avó se inicia na notícia da gestação da adolescente. Por meio dos depoimentos foi possível perceber que este momento suscita diferentes sentimentos e pensamentos nas mães das adolescentes, que não esperavam ser avó neste momento de vida em função da própria idade e de não associar a representação de avós com a sua imagem pessoal. Destaca-se a ideia da avó como segunda mãe dos bebês elencada por alguns participantes, o que pode evidenciar as implicações e envolvimento que essas mulheres terão com seus netos e suas filhas.

Como limitação desse estudo sua característica transversal, no sentido de que não foi possível acompanhar essas mulheres no período de nascimento da criança, bem como, em momentos subsequentes a esse evento. Assim, sugere-se a realização de pesquisas longitudinais sobre o tema, de modo possibilitar um maior acompanhamento dessas mulheres em vários momentos do processo de torna-se e ser avó. Além disso, sugere-se a realização de estudos com a percepção das avós maternas e paternas, como também, dos avôs maternos e paternos no contexto da gravidez adolescente.

Ressalta-se a necessidade maior atenção aos familiares envolvidos no contexto da gravidez adolescente, o que pode contribuir para entendimento da dinâmica familiar dos adolescentes, o que se constitui um aspecto importante no planejamento, controle e execução de programas, intervenções de prevenção à gravidez na adolescência e estímulo à participação dos pais das adolescentes nas ações e orientações relativas a conversar sobre sexualidade nesta fase do desenvolvimento. Destaca-se que a realização dessa pesquisa ocorreu nas Unidades Básicas de Saúde, espaços potenciais para a realização de ações com foco na promoção da saúde, ações educativas de prevenção da gravidez na adolescência, de práticas 
sexuais seguras e prevenção das doenças sexualmente transmissíveis tendo como alvo o público adolescente e seus familiares.

Este estudo pretende chamar atenção para a necessidade de realização de mais pesquisas que contemplem a dinâmica familiar, bem como, outros membros da família, como os avôs, por exemplo, o estudo do tornar-se avô neste contexto. Além disso, atentar a outros aspectos como a saúde das avós, coparentalidade, impacto da notícia da gravidez no relacionamento avó-neto, e ser avó no contexto da maternidade adolescente.

\section{Referências}

Álvarez-Nieto, C., Pastor-Moreno, G., Linares-Abad, M., Serrano-Martos, J., \& RodríguezOlalla, L. (2014). Maternidad temprana: Percepciones e implicaciones de las madres de las adolescentes. Matronas Profesíon, 15(3), 88-94. Recuperado de http://www.federacion-matronas.org/wp-content/uploads/2018/01/originalmaternidad-temprana.pdf

Becker, A. C., \& Falcão, D. V. S. (2016). O envelhecimento, a velhice e o significado de ser avô(ó) na perspectiva de atores profissionais idosos. Revista Brasileira de Geriatria e Gerontologia, 19(2), 289-302. doi:10.1590/1809-98232016019.140212

Bossa, A. R. G., \& Aponte, M. R. E. (2010). Prácticas de crianza de madres adolescentes de la ciudad de Diutama, Colombia, Investigación y Educación en Enfermaria, 28(3), 398-404. Recuperado de http://www.scielo.org.co/pdf/iee/v28n3/v28n3a10.pdf

Brasil. Ministério da Saúde. Departamento de Ações Programáticas Estratégicas. (2006). Modelo teórico e referencial Saúde sexual e saúde reprodutiva de adolescentes e jovens. Brasília, D.F.: Ministério da Saúde. Recuperado de http://bvsms.saude.gov.br/bvs/publicacoes/saude_sexual_saude_reprodutiva.pdf

Brasil. (2012). Resolução n. ${ }^{\circ}$ 466/12, de 12 de dezembro de 2012. Brasília, D.F.: Conselho $\begin{array}{llll}\text { Nacional de } & \text { Saúde. } & \text { Recuperado }\end{array}$ http://conselho.saude.gov.br/ultimas_noticias/2013/06_jun_14_publicada_resolucao.ht $\mathrm{ml}$

Brás, C., \& Pereira, A. (2011). Promoção da saúde de grávidas adolescentes: Estudo prévio de identificação de necessidades. Millenium, 40(16), 69-81. Recuperado de https://revistas.rcaap.pt/millenium/article/view/8220

Cardoso, A. R. (2011). Avós no século XXI: Mutações e rearranjos na família contemporânea. Curitiba: Juruá. 
Cardoso, A. R., \& Brito, L. M. T. (2014). Ser avó na família contemporânea: Que jeito é esse? Psico USF, 19(3), 433-441. doi:10.1590/1413-82712014019003006

Charmaz, K. (2009). A construção da teoria fundamentada: Guia prático para análise qualitativa. Porto Alegre: Artmed.

Cunha, V. S., \& Wendling, M. I. (2011). Aspectos transgeracionais da gravidez na adolescência na perspectiva de mães e filhas residentes em Parobé e Taquara (RS). Contextos Clínicos, 4(1), 28-41. doi:10.4013/ctc.2011.41.04

Deus, M. D., \& Dias, A. C. G. (2016). Avós Cuidadores e Suas Funções: Uma Revisão Integrativa da Literatura. Pensando Famílias, 20(1), 112-125. Recuperado de http://pepsic.bvsalud.org/scielo.php?script=sci_arttext\&pid=S1679494X2016000100009

Dias, C. M. S. B., Hora, F. F. A., \& Aguiar, A. G. S. (2010). Jovens criados por avós e por um ou ambos os pais. Psicologia: Teoria e Prática, 12(2), 188-199. Recuperado de http://pepsic.bvsalud.org/scielo.php?script=sci_arttext\&pid=S151636872010000200013

Dias, A. C. G., Patias, N. D., Gabriel, M.R., \& Teixeira, M. A. P. (2012). A perspectiva dos pais diante da gestação na adolescência. Revista de Ciências Humanas, 46(1), 143 164. doi:10.5007/2178-4582.2012v46n1p143

Dias, A. C. G., \& Teixeira, M. A. P. (2010). Gravidez na adolescência: Um olhar sobre um fenômeno complexo. Paidéia, 20(45), 123-131. doi:10.1590/S0103863X2010000100015

Fernandes, A. O., Santos Júnior, H. P. O., \& Gualda, D. M. R. (2012). Gravidez na adolescência: Percepções das mães de gestantes jovens. Acta Paulista de Enfermagem, 25(1), 55-60. doi:10.1590/S0103-21002012000100010

Frisman, G. H, Eriksson, C., Pernehed, S., \& Mörelius, E. (2012). The experience of becoming a grandmother to a premature infant: A balancing act, influenced by ambivalent feelings. Journal of Clinical Nursing, 21, 3297-3305. doi:10.1111/j.13652702.2012.04204.x

Gonçalves, H., \& Knauth, D. R. (2006). Aproveitar a vida, juventude e gravidez. Revista de Antropologia, 49(2), 625-643. doi:10.1590/S0034-77012006000200004

Guest, G., Bunce, A., \& Johnson, L. (2006). How many interviews are enough? An experiment with data saturation and variability. Field Methods, 18(1), 59-82. doi:10.1177/1525822X05279903 
Hoga, L. A. K., Borges, A. L. V., \& Alvarez, R. E. C. (2009). Gravidez na adolescência: Valores e reações dos membros da família. Acta Paulista de Enfermagem, 22(6), 779785. doi:10.1590/S0103-21002009000600009

Kipper, C. D. R., \& Lopes, R. S. (2006). O tornar-se avó no processo de individuação. Psicologia: Teoria e Pesquisa, 22(1), 29-34. doi:10.1590/S0102-37722006000100004

Mainetti, A. C., \& Wanderbroocke, A. C. N. S. (2013). Avó que assumem a criação dos netos. Pensando Famílias, 17(1), 87-98. Recuperado de http://pepsic.bvsalud.org/scielo.php?script=sci_arttext\&pid=S1679494X2013000100009

Munslinger, I. M., Silva, S. M., De Bortoli, C. F. C., \& Guimarães, K. B. (2016). A maternidade na perspectiva de mães adolescentes. Revista Brasileira em Promoção da Saúde, 29(3), 357-363. doi:10.5020/18061230.2016.p357

Pinto, K. L. B., Arrais, A, R., \& Brasil, K. C. T. R. (2014). Avosidade X Maternidade: A avó como suporte parental na adolescência. Psico-USF, 19(1), 37-47. doi:10.1590/S141382712014000100005

Santos, A. L., Teston, E. F., Cecílio, H. P. M., Serafim, D., \& Marcon, S. S. (2015). Grandmothers' involvement in the care of children of adolescent mothers. REME: Revista Mineira de Enfermagem, 19(1), 55-59. doi:10.5935/1415-2762.20150005

Silva, D. V., \& Salomão, N. M. R. (2003). A maternidade na perspectiva de mães adolescentes e avós maternas dos bebês. Estudos de Psicologia, 8(1), 135-145. doi:10.1590/S1413-294X2003000100015

Shlomo, S. B., Bem-Ari, O. T., Findler, L., Sivan, E., \& Dolizki, M. (2010). Becoming a grandmother: Maternal grandmothers' mental health, perceived costs, and personal growth. Social Work Research, 34(1), 45-57. doi:10.1093/swr/34.1.45

Souza, T. A., Brito, M. E. M., Frota, A. C., \& Nunes, J. M. (2012). Gravidez na adolescência: Percepções, comportamento e experiência de familiares. Revista da Rede de Enfermagem do Nordeste, 13(4), 794-804. doi:10.15253/rev\%20rene.v13i4.4035

Tarozzi, M. (2011). O que é groundedtheory: Metodologia de pesquisa e de teoria fundamentada nos dados. Petrópolis, RJ: Vozes.

Taubman, O., Ben-Ari, O. T., Shlomo, S. B., \& Findler, L. (2012). Personal growth and meaning in life among first-time mothers and grandmothers. Journal of Happiness Studies, 13(5), 801-820. doi:10.1007/s10902-011-9291-5

Valila, M. G., Moraes, N. A., Dalbello, N. N., Vieira, S. S., Beretta, M. I. R., \& Dupas, G. (2011). Gravidez na adolescência: Conhecendo a experiência da família. Revista 
Mineira de Enfermagem da Escola de Enfermagem da Universidade Federal de Minas Gerais, 15(4), 556-566. Recuperado de http://www.reme.org.br/artigo/detalhes/70

Zanatta, E., \& Arpini, D. M. (2017). Conhecendo a imagem, o papel e a relação avó-neto: A perspectiva de avós maternas. Revista Estudos e Pesquisas em Psicologia, 17(1), 343363. Recuperado de https://www.epublicacoes.uerj.br/index.php/revispsi/article/view/35164/24865

Zeiders, K. H., Umaña-Taylor, A. J., Jahromi, L. B., \& Updegraff, K. A. (2015). Grandmothers' familism values, adolescent mothers' parenting efficacy, and children's well-being. Journal of Family Psychology, 29(4), 624-634. doi:10.1037/fam0000103

\section{Endereço para correspondência}

\section{Meiridiane Domingues de Deus}

Universidade Federal de Santa Catarina

Centro de Filosofia e Ciências Humanas

Campus Universitário, Trindade, Florianópolis, SC - Brasil. CEP 88040-500

Endereço eletrônico: meiridianeddeus@gmail.com

\section{Ana Cristina Garcia Dias}

Rua Ramiro Barcelos, 2600 sala 206, Rio Branco, Porto Alegre, RS - Brasil. CEP 9003-500

Endereço eletrônico: anacristinagarciadias@gmail.com

Recebido em: 06/02/2019

Reformulado em: 03/12/2019

Aceito em: 03/01/2020

\section{Notas}

* Psicóloga, especialista em Gestão de Organização Pública em Saúde/UFSM, mestre em Psicologia/UFSM, doutoranda no Programa de Pós-graduação em Psicologia/UFSC.

** Psicóloga, mestre em Psicologia/UFRGS, doutora em Psicologia/USP e professora do Programa de Pósgraduação em Psicologia/UFRGS. Bolsista Produtividade CNPq 1-D.

Financiamento: O presente trabalho foi realizado com apoio da Coordenação de Aperfeiçoamento de Pessoal de Nível Superior Brasil (CAPES) Código de Financiamento 001. Projeto CNPq ; Projeto CNPq 405731/2012-4.

Este artigo de revista Estudos e Pesquisas em Psicologia é licenciado sob uma Licença Creative Commons Atribuição-Não Comercial 3.0 Não Adaptada. 